as a deficiency during cross-examination, the limitations of such techniques must be outlined. These include recall bias, bias motivated by gain, social desirability and contamination of personality evaluations by mood. A further problem with structured measures is confusing their use as diagnostic tools with their use as severity measures: for example, a Beck Depression Inventory score of 17 is not diagnostic of depressive illness.

\section{Hurrying the witness}

This technique is designed to obtain contradictory evidence. When questions are being thrown in quick succession, it may be necessary to ask the judge's permission for time to consider the question carefully and reflectively. Establishing eye contact with the judge will also slow the pace.

\section{Conclusions}

There is a well-developed case law in relation to expert witnesses. At its core is the belief that the expert is there to assist the court in matters of expertise not directly available to it. The expert must be well versed in the topic under consideration, both clinically and academically. It is essential to undertake careful preparation before giving evidence and to observe the rules of evidence.

\section{Multiple choice questions}

1 The expert witness:

a has a right to be present at the hearing even when it is held in camera

$\mathrm{b}$ is the only witness who does not have to switch off pagers and mobile phones

c can always communicate verbally with senior counsel during the hearing d can seek advice if there is an adjournment during his or her cross-examination

e cannot discuss his or her evidence during an adjournment of cross-examination.

2 In the witness box:

a the witness usually stands (in an English court)

b the witness always faces counsel

c the witness always faces the judge

d the witness will not be interrupted

e the witness may not drink water.

3 Examination-in-chief:

a begins by summarising the main findings on examination

b includes providing information about the witness's expertise in the area

c mainly comprises leading questions

$\mathrm{d}$ is best dealt with by reading directly from the medicolegal report

e prohibits the witness from referring to notes.

4 During cross-examination:

a the expert may have his or her expertise challenged

$b$ the expert will never have his or her method of assessment questioned

c the expert should take umbrage if his or her conclusions are challenged

d the expert should seek the judge's permission to complete an answer if interrupted

e the expert should be prepared to change his or her mind in certain circumstances.

\section{MCQ answers}

$\begin{array}{lllll}1 & & 2 & 3 & 4 \\ \text { a F } & \text { a T } & \text { a F } & \text { a T } \\ \text { b F } & \text { b F } & \text { b T } & \text { b F } \\ \text { c F } & \text { c F } & \text { c F } & \text { c F } \\ \text { d F } & \text { d F } & \text { d F } & \text { d T } \\ \text { e T } & \text { e F } & \text { e F } & \text { e T }\end{array}$

\title{
INVITED COMMENTARY ON Expert testimony in court
}

\section{The Scottish courts}

Patricia Casey's papers (2003a,b, this issue) cover the situation regarding expert witnesses in England and Wales and in Ireland. The situation in Scotland is outlined below.
Most psychiatrists in Scotland will gain experience of providing reports or appearing in court as part of their routine clinical work for the criminal courts, for non-judicial bodies such as the Children's Panel and in applications for compulsory detention under the Mental Health (Scotland) Act 1984. It 
should be accepted as part of normal clinical work. Normally this work proceeds, in customary Scottish manner, without fuss or drama. Sometimes there are serious difficulties; most are predictable but some are not. Oral psychiatric evidence in Scottish courts is the exception rather than the rule. A clear, concise and well-written report will often avert the need for its writer to attend court to give oral evidence.

\section{Criminal cases}

The Crown makes requests for reports on untried defendants through the local procurator fiscal. Postconviction reports are requested by the sentencer, usually a sheriff, through the sheriff clerk's office. A relatively small proportion of reports are requested by defence lawyers. The Crown Office is the central office responsible for administering all procurator fiscal offices. It issues a finance manual to procurators fiscal, setting out the criteria for, and scale of fees payable to, professional and expert witnesses, including doctors. Psychiatrists providing court reports for the Crown are normally regarded as professional witnesses and paid accordingly. Expert witness status applies in those cases where the Crown requests an opinion from a psychiatrist because of his or her special knowledge of the specific subject at issue. Expert witness status is a matter for decision by the Crown Office and must be agreed before carrying out the assessment or giving the opinion.

Defence solicitors obtain psychiatric reports from psychiatrists of their choice. The suitability and expertise of the psychiatrist is a matter for consideration by the instructing solicitor. Fees are set down by the Scottish Legal Aid Board or are negotiated individually. Clinical psychologists are increasingly being called to give evidence in the criminal courts. A recent landmark ruling, Galbraith v. Her Majesty's Advocate, Appeal No. C353/99 (http://www. scotcourts.gov.uk/opinions/C353A_99.html) established a new definition of diminished responsibility. This permits evidence on abnormality of mind to be given by psychologists and allows mental conditions recognised by 'the appropriate science' to be included within its ambit. If the floodgates open, psychiatrists may find themselves washed well downstream and possibly out of sight, below the water.

Where the accused is remanded in custody, there is a strict timescale for the preparation of reports. Summary cases come to trial within 40 days and solemn cases within 110 days. The rules of evidence in Scotland are entirely different from those of England and Wales. The statements of witnesses are known as 'precognitions' and the written evidence, reports and other material that will be used in court are the 'productions'. These are not made available routinely to psychiatrists preparing reports. Indeed, the information provided by the instructing agent is sometimes meagre. The general rule is 'ask for what you want'. If your report is based on limited information from other sources, you should state this clearly in it, particularly where information from other sources might materially affect your opinion. It is customary to state that the report is given 'on soul and conscience', i.e. that you believe the report to be a true statement of your opinion.

Undisputed cases commonly proceed without hearing oral evidence. If Crown and defence dispute a plea (e.g. of unfitness to plead, insanity at the time of the offence or diminished responsibility), then oral evidence will be essential. Expert witnesses can expect a searching examination of their professional credentials, their opinions and the methods by which they reached those opinions. Witnesses are not permitted to hear the evidence of earlier witnesses in the case unless they are specifically requested to do so.

\section{Civil cases}

The common issues in civil court work include:

- alleged psychiatric clinical negligence;

- the psychiatric consequences of accidents, childhood abuse, work-related stress and non-psychiatric clinical negligence;

- mental health problems affecting employment;

- compulsory child-adoption procedures.

Experts need to possess skills and knowledge in the relevant area and the ability to write a report that is balanced, objective, supported by the factual information available and clear in its conclusions. Lawyers would add that it also needs to be delivered on time.

Scotland has no equivalent of the Civil Procedure Rules introduced following the Woolf Report (Lord Chancellor's Department, 1996): experts are instructed by the pursuer or defender. Joint instruction of a single expert is rare but there is a commonly used procedure for lawyers to submit to the court a 'joint minute' of the evidence on which both sides agree.

Psychiatrists need to be aware of their abilities and limitations. You should be satisfied that you meet the court's reasonable expectation for relevant special expertise. This is not defined in law, but the court is entitled to establish your credentials and identify any potential deficits in knowledge or relevant experience. In writing their opinions, judges take into account the strengths and weaknesses of expert witnesses and routinely include comments on how influential or otherwise they found the expert's oral evidence. 
Psychiatric witnesses in court need to cultivate a calm, professional and confident manner. You must give all questions proper consideration, then answer with authority. You are advised to take only minimal material with you into the witness box and not to refer to any document without first seeking permission of the judge. You will be asked questions about your report, which is almost bound to be a court production available in advance to both sides. You will incur irritation if you start to thumb through case notes unless these are a production and have been handed to you in court. If you are uncertain, discuss the matter in advance with whoever is instructing you. You should leave the court feeling that you have passed a challenging viva - hopefully you have.

\section{References}

Casey, P. (2003a) Expert testimony in court. 1: General principles. Advances in Psychiatric Treatment, 9, 177-182.

- (2003b) Expert testimony in court. 2: In the witness box. Advances in Psychiatric Treatment, 9, 183-187.

Lord Chancellor's Department (1996) Public Access: Final Report to the Lord Chancellor on the Civil Justice System in England and Wales (Woolf Report). London: Stationery Office.

Derek Chiswick Consultant Forensic Psychiatrist and Lead Clinician at the Orchard Clinic Medium Secure Unit, Royal Edinburgh Hospital, Edinburgh EH10 5HF, UK (e-mail Derek.Chiswick@lpct.scot.nhs.uk).

\section{INVITED COMMENTARY ON Expert testimony in court}

Those who possess expertise or experience of a scientific or technical nature are often called to give evidence as a witness in a court or tribunal (in Scotland, he or she is known as a 'skilled witness'). In so far as the expert witness expresses an opinion, that evidence is, strictly speaking, an exception to the hearsay rule. However, since the 16th century, the courts have admitted opinion evidence from anyone, not just a 'professional', who can assist the court on a scientific or technical matter which is an issue in the case and is beyond the knowledge of the court or tribunal. Frequently, the expert witness will be giving evidence as to fact as well as opinion. For example, the forensic pathologist who conducts a post-mortem examination will be able to give a factual description of the condition of the body and, at the same time, give an expert opinion on the cause of death. The forensic psychiatrist will similarly describe what has been determined about the patient on examination of his or her symptoms and express an opinion on the patient's mental health. There will be cases where the expert is supplied with factual data on which to express an expert opinion.

\section{Mental condition and fitness to plead}

Psychiatrists and psychologists are frequently called to give evidence about an accused or convicted person's mental condition at the time of the criminal event or at the time of trial. In the former instance, the issue will be one of insanity (rarely a defence plea since the abolition of the death penalty in 1965) or, since the Homicide Act 1957, diminished responsibility, which, if confirmed, reduces the offence of murder to one of manslaughter.

Occasionally, the issue will be the accused person's fitness to plead. From the early 19th century, doctors have been called to deal with the question of whether the defendant 'has significant intellect' to understand the evidence and to give it and, accordingly, to be able to instruct his or her legal representatives regarding defence. In $R v$. Johnson [2002], on a reference from the Criminal Cases Review Commission of a conviction for murder 26 years previously, the Court of Appeal (Criminal Division) accepted the evidence of Professor Kopelman and Dr Joseph (both Fellows of the Royal College of Psychiatrists) that the accused was psychotic and thus unable to participate effectively at his trial, at least at the moment (if not earlier) when he dismissed his legal representatives without any ostensible explanation. In accepting the evidence of the two psychiatrists, based merely on a study of the court reports of the trial, the court nevertheless overrode the evidence of a prison medical officer who, on a pre-trial examination of the defendant in prison, considered that there was no sign of mental illness and no suicidal thoughts. (The prison medical officer is still alive, but was not called by the Crown.) 